\title{
La formación del Gran Buenos Aires (Argentina) a través del análisis de las normativas y códigos vigentes (1910-1927)
}

\author{
A constituição da Grande Buenos Aires (Argentina) por meio da análise das \\ normas e códigos vigentes (1910-1927) \\ The formation of Greater Buenos Aires (Argentina) analyzed trough land \\ regulations and urban legislation (1910 and 1927)
}

Ana Gómez Pintus ${ }^{[0]}$, Noelia Fernández ${ }^{[b]}$

[a] Universidad Nacional de La Plata (UNLP), La Plata, Buenos Aires, Argentina

[b] Universidad Nacional de Quilmes (UNQ), Buenos Aires, Argentina

\section{Resumen}

Desde comienzos el siglo XX se asistió en la periferia de la Ciudad de Buenos Aires a la inserción de núcleos de barrio parque y fin de semana como parte del proceso de modernización de la ciudad y de sus redes de transporte. En este marco, el trabajo que presentamos se propone analizar el proceso de urbanización de dichas áreas haciendo hincapié en la relación entre las formas privadas de urbanización y las problemáticas que subyacían en relación a la acción del Estado. Metodológicamente, se trabajará sobre el análisis, por un lado, de un conjunto de leyes y códigos vigentes para el área y por el otro sobre las transformaciones efectivas del territorio. Matizando lo que proponen las visiones más tradicionales, que dan un valor superlativo a las prácticas privadas, proponemos que el "crecimiento desordenado" del GBA obedeció a la dificultad de las reparticiones gubernamentales y de la normativa a leer las coordenadas específicas y adaptarse a los nuevos modelos de expansión.

Palabras clave: Expansión urbana. Gran Buenos Aires. Legislación.

\section{Resumo}

Este artigo se centra em uma investigação cujo objetivo principal é avaliar a inserção dos núcleos de condomínios e casas de verão ou de veraneio na formação da área metropolitana de Buenos Aires durante a primeira metade do século XX. Analisar esse processo implica, entre outros temas, considerar as problemáticas da divisão dos lotes que subjaziam em relação à ação do Estado. Por essa razão, propõe-se a análise de um conjunto de leis e códigos vigentes para essa área entre os anos 1910 e 1927. Especialmente, será feita uma revisão da construção e do funcionamento dessas normativas, presumindo que as origens do "crescimento caótico e hipertrófico

AGP: Doctora en Arquitectura; Investigadora del instituto de Historia, Teoría y Praxis de la Ciudad (HiTePAC), Facultad de Arquitectura y Urbanismo (FAU), Universidad Nacional de La Plata (UNLP); Investigadora Asistente del Consejo Nacional de Investigaciones Científicas y Técnicas (CONICET), e-mail: agomezpintus@gmail.com

NF: Licenciada en Ciencia Política (Universidad de Buenos Aires); Magíster en Ciencias Sociales con mención en Historia Social (Universidad Nacional de Luján) y doctoranda en Ciencias Sociales (Universidad Nacional de Quilmes); Becaria doctoral del Consejo Nacional de Investigaciones Científicas y Técnicas (CONICET); Investigadora en formación del Instituto de Estudios sobre la Ciencia y la Tecnología (IESCT) y del Centro de Historia de los Intelectuales (CHI) de la Universidad Nacional de Quilmes (UNQ), e-mail: noefernandez.16@gmail.com 
da Grande Buenos Aires (GBA)" - como definido, em 1948, pela Comissão Assessora da GBA - devem-se não pela falta de controles estatais, mas sim pela irrelevância das normativas, isto é, a incapacidade delas em se sustentarem através do tempo, dificultando a adaptação aos novos modelos de expansão.

Palavras-chave: Expansão urbana. Grande Buenos Aires. Legislação.

\begin{abstract}
This paper takes part of a broader investigation which main objective is to evaluate the impact of garden suburbs and week-end houses areas developed by private enterprises within Buenos Aires' Metropolitan Area between 1910 and 1950. To look deeply into this matter implies considering, among other subjects, those problems related to land subdivisions and State regulations. From this perspective, we will seek into land regulations and urban laws affecting the area during the first half of the twentieth Century. The main objective is to focus on the formulation and implementation of those regulations, assuming that the chaotic sprawl of the area- as defined by the Comisión Asesora del GBA in 1947- is due not to the lack of regulations but, on the contrary, to its capacity to stick into everyday practice, difficulting any process of transformation or adaptation to new ways of sprawl.
\end{abstract}

Keywords: Urban sprawl. Buenos Aires' Metropolitan Area. Legislation.

\section{Introducción}

En el Gran Buenos Aires (GBA) una porción importante del crecimiento metropolitano se ha dado principalmente sobre la base de loteos particulares ${ }^{1}$. En el marco de un proceso de expansión más amplio, a partir de 1910 se asistió al crecimiento de un tipo particular de suburbio moderno, articulado en torno a la residencia de verano o fin de semana en combinación con la oferta deportiva o paisajística promovidas en determinadas áreas. Impulsado principalmente por agentes privados - dueños de la tierra, inmobiliarias e inversores - que buscaban obtener ganancias con los procesos de subdivisión del suelo, la inclusión de

1 Utilizamos la denominación GBA, aunque este sector recién tomaría reconocimiento oficial a partir del decreto provincial 70/48 del 8 de enero de 1948. Este establecía al área del "Gran Buenos Aires" incluyendo a la Capital federal y a los diecisiete partidos que habían formado parte del relevamiento censal de 1947. Sin embargo, otro decreto $n^{\circ}$ 23.438 del 6 de octubre de 1949 otorgó estatus jurídico a este territorio restringido, pero excluyó a la Capital Federal. Sobre estos temas, véase: Caride (1977) decreto provincial 70/48 del 8 de enero de 1948. Este establecía al área del "Gran Buenos Aires" incluyendo a la Capital federal y a los diecisiete partidos que habían formado parte del relevamiento censal de 1947. Sin embargo, otro decreto $n^{\circ} 23.438$ del 6 de octubre de 1949 otorgó estatus jurídico a este territorio restringido, pero excluyó a la Capital Federal. Sobre estos temas, véase: Caride (1977). estos emprendimientos al proceso expansivo colaboró en la construcción de lo que ya se perfilaba como un proceso desordenado y fragmentario.

Uno de los interrogantes en los que se enmarca este trabajo alude al rol que jugaron los núcleos y emprendimientos suburbanos de fin de semana en la construcción del área metropolitana de Buenos Aires. Analizar el proceso de formación del GBA, aunque solo sea desde la perspectiva que impone el estudio de los loteos de fin de semana, supone considerar diferentes aspectos: morfológicos, materiales, sociales y políticos. Entre ellos, pondremos la lupa sobre las problemáticas de los loteos que subyacían en relación a la acción del Estado - objetivado en instituciones, organismos públicos y normativas $-\mathrm{y}$ los demás agentes involucrados en la formación del territorio. Para ello, nos centramos en los procesos y modalidades de acción que estuvieron por detrás de las transformaciones materiales del territorio. En tal sentido, partimos de una pregunta inicial: ¿cómo se construyen las normativas, qué ideas de ciudad subyacen en ella y cómo dialogan con la construcción real del territorio?

En relación al proceso de formación del GBA, los primeros estudios se remontan a los años setenta, cuando desde la esfera del urbanismo varias investigaciones intentaban reconocer la estructura interna de la ciudad latinoamericana o explorar los modelos de ocupación territoriales (Schteingart \& 
Torres, 1972; Yujnovsky, 1971; Vapñarsky, 2000; Sargent, 1974). Más tarde, los estudios se centraron en los modos de producción y transformación del suelo (Clichevsky, 1975). Más allá de algunos avances de finales de los años noventa, la historiografía se ha centrado en procesos más generales, destacando los procesos de suburbanización populares e industriales, haciendo a un lado la cantidad de situaciones diversas y particulares que confluyen en este mismo territorio.

Se ha hecho especial hincapié en el carácter privado de la expansión. Por las características que este proceso adquirió en el área metropolitana de Buenos Aires, donde la tierra suburbana pertenecía en su mayor parte a sectores privados, se fortaleció la hipótesis de que la ciudad ha sido construida básicamente utilizando los mecanismos del mercado, resultado de las relaciones de competencia entre actores individuales (dueños de la tierra, promotores y agentes inmobiliarios) que buscaron, primordialmente, la obtención de beneficios económicos. En esta línea, el trabajo de Clichevsky (1975) sobre el mercado de tierras en la expansión de Buenos Aires, asigna un rol menor al Estado en la producción de suelo, y pone el énfasis en tres agentes del sector privado: 1. los propietarios de la tierra rural, 2. los inversionistas individuales y 3. las empresas urbanizadoras o comercializadoras.

Por su parte, Torres (1993) si bien no se concentra en este aspecto de la expansión, reconoce que el Estado adoptó una política de laissez faire en relación al control de los usos del suelo y pone el acento en el papel que jugaron las inversiones especulativas en general, y las empresas de transporte - más en particular las líneas de colectivos - que estructuraron las áreas de crecimiento. Por último, el trabajo más contemporáneo de Lanciotti (2009) pone en evidencia la importancia del empresariado inmobiliario en la formación del mercado de tierras de las ciudades argentinas.

Como ya adelantamos, resulta necesario analizar cuál fue el rol desempeñado por el Estado provincial y qué capacidad tuvo para generar marcos de regulación, advirtiendo que interviene en los procesos de producción de tierra urbana en dos ámbitos bien específicos: por un lado, a través de la intervención directa, por ejemplo con la construcción de obra pública, y por otro, de manera indirecta, a través del control que ejerce mediante, entre otras cuestiones, la construcción de un cuerpo legal de reglamentaciones. Nos proponemos, entonces, revisar el papel del Estado y su dinámica institucional, a fin de matizar las visiones más extendidas que desestiman la implicancia de las políticas públicas y las acciones legislativas del Estado en materia de ordenamiento territorial. Intentamos, por lo tanto, reconocer la complejidad de cuestiones que entran en juego al momento de elaborar e implementar políticas públicas y las dificultades que impone el propio escenario político de la provincia.

El Estado ha sido objeto de estudio de una profusa literatura teórica y ha permanecido en el eje de las reflexiones políticas y sociales contemporáneas ${ }^{2}$. Como nos recuerda Skinner (2003) el significado del concepto "Estado", clave para la teoría política y las ciencias sociales, es complejo e histórico, lo que ha provocado numerosas reconceptualizaciones. A partir de la década de 1980, numerosos estudios provenientes fundamentalmente de las Ciencias Sociales se propusieron revisar el rol del Estado y su dinámica institucional, dejando de lado la interpretación del mismo como un fenómeno marginal entre grupos de interés o como un acuerdo entre elites dominantes. Autores como Skocpol et al. (1985) - referentes de lo que se denominó "neoinstitucionalismo" - plantearon el "regreso" del Estado como actor político-institucional con objetivos propios que no necesariamente refleja de modo mecánico los intereses de sectores hegemónicos, en contraposición de las teorías dominantes de las ciencias sociales de las décadas de 1950 y 1960 (especialmente el pluralismo y el estructural funcionalismo). Esta perspectiva nos aporta conceptos tales como el poder, la autonomía, la capacidad y la fortaleza del Estado, importantes para problematizar y comprender la dinámica de las acciones que en materia territorial desarrolló el Estado provincial $^{3}$. No obstante, esta mirada se complejiza

2 Sobre la producción de las ciencias sociales abocadas al estudio del Estado en Argentina, véase: Bohoslavsky \& Soprano (2010). Los autores realizan un breve recorrido por las disciplinas sociales que lo han estudiado como la ciencia política, las relaciones internacionales, la antropología social y la historia.

3 Conceptos como autonomía o capacidad del Estado son empleados para analizar las variables que entran en juego entre la elaboración de políticas públicas y su puesta en práctica. Se entiende que un Estado puede ser denominado fuerte o autónomo en la medida en que puede formular y perseguir metas que no constituyan meramente el reflejo de las exigencias o intereses de los grupos o clases sociales dominantes. La capacidad del Estado, por otra parte, hace referencia a su facultad para implementar políticas públicas (Sikkink \& Wolfson, 1993). 
con las ideas centrales de Mann (1991) que destaca la "impureza" del Estado, en el sentido de que no puede estar totalmente aislado de grupos sociales o privados en tanto distintas partes de su cuerpo político están abiertas a la penetración de diferentes redes de poder. Una mirada más reciente sobre el Estado, propuesta por Bourdieu \& Wacquant (2005), resulta importante para comprender la dinámica de los procesos de regulación estatal que observamos. Desde otra matriz de interpretación, los autores rechazan un concepto tradicional del Estado que lo exhibe como una estructura burocrática relativamente coherente y regulada por pautas que el mismo se impone y que se mantiene en una relación de externalidad con las fuerzas del afuera que están, a su vez, claramente identificadas y definidas. Desde una perspectiva "relacional", el Estado más bien se presenta como un conjunto de "campos burocrático administrativos" dentro de los cuales agentes y grupos de agentes gubernamentales y no gubernamentales luchan por una forma particular de autoridad que consiste en el poder de "ordenar" a través de la legislación o de medidas administrativas, en síntesis, todo aquello que normalmente se coloca bajo el rubro de las políticas de Estado como esfera particular de prácticas relacionadas. Esta perspectiva nos permite pensar que la construcción del cuerpo legal promovida por el Estado provincial (cuya finalidad era regular y ordenar el territorio) también implicó una forma de lucha por definir los alcances reales del poder estatal frente a los intereses privados.

Asimismo, como recuerda Persello (2006) la objetivación del Estado en instituciones y aparatos sigue constituyendo un espacio escasamente reconstruido y problematizado. Siguiendo los postulados de Rosanvallon (1989) en L'etat en France, la autora señala que:

[...] comprender la historia del Estado - dice Rosanvallon - implica abordar no sólo su forma política, la construcción del gobierno representativo - proceso de democratización - sino el modo en que se instaura el proceso de racionalización, la constitución del aparato administrativo; y más aún, considerar la articulación específica que en cada coyuntura se produce entre gobierno representativo y burocracia estatal, es decir, el modo en que se realiza la representación, se designan funcionarios, se elaboran y se implementan políticas públicas [...] (Persello, 2006).
Nuestra intención radica, también, en observar el resultado material del cruce entre un determinado gobierno y la burocracia estatal (representada por cuerpos técnicos constituidos en torno a un saber específico) desarrollado en contextos políticos e históricos específicos (1913 y 1927).

Cabe destacar que desde los estudios urbanos y culturales los trabajos de Mazza (1997), Aliata (2004) y Ballent (2008) discutieron las investigaciones que desestiman el rol de las políticas públicas y de las acciones legislativas en materia de ordenamiento territorial. En el libro La Ciudad de Papel (Mazza, 1997) Mazza y varios autores proponen un análisis histórico de las normativas y planes pensados para la ciudad de Mar del Plata, entendiendo que constituyen un momento de reflexión, planificación de la urbanización, diferente de aquel otro en el que las acciones constituyen la realidad histórica de la materialidad urbana (proceso de urbanización). Aliata presenta, entre otras cuestiones, una mirada basada en el estudio de las tensiones que atravesó el desarrollo de la ciudad de Buenos Aires entre 1821 y 1823, a través de los debates de proyectos (políticos, edilicios y arquitectónicos) y de los problemas que los actores debieron afrontar. Por su parte, Ballent ha demostrado cómo la creación y las acciones y políticas promovidas por un organismo estatal (la Dirección Nacional de Vialidad) han sido decisivas en las transformaciones territoriales argentinas suscitadas en los años treinta. Sin embargo, si bien somos conscientes que dichos estudios se enmarcan en contextos históricos, políticos y estatales muy diferentes al nuestro, sirven como marco de referencia para comprender el rol del aparato estatal respecto de las transformaciones territoriales.

En síntesis, en nuestro trabajo confluyen las miradas desde la historia urbana (que ponen el foco en los procesos y actores, fundamentalmente del ámbito privado) con aquellas propuestas desarrolladas por las ciencias sociales, que consideran el carácter complejo del Estado y la diversidad de cuestiones-actores que entran en juego a la hora de formular e implementar políticas y acciones. A partir de esta confluencia, se dirime la necesidad de un análisis que ponga en relieve el papel de los elencos políticos y técnicos frente a nuevos escenarios y requerimientos, y de la interlocución de los actores y agencias estatales con otros actores y esferas no estatales. Por esta razón, cabe identificar a las diferentes figuras públicas y privadas involucradas en los procesos de formación 
del suelo; las gestiones necesarias para la aprobación de los loteos; las agencias provinciales y municipales comprometidas en este proceso; y los resultados de dichas intersecciones. El objetivo de este análisis, entonces, es examinar el vínculo entre la normativa (y la idea de ciudad que esta busca imponer) y la construcción real del territorio (su puesta en práctica).

En tal sentido, nuestra hipótesis sugiere que el proceso de crecimiento fragmentario y desordenado que es posible verificar en la formación de GBA, obedece - en cuanto compete a las acciones del Estado en materia legislativa - a la dificultad de interpretar o saber "leer" las coordenadas de la expansión. Esto dio como resultado una reglamentación amplia y rígida, que difícilmente se adecuaba a las diversas situaciones que se presentaban en elárea metropolitana. La idea de ciudad que queda congelada en la normativa se sostiene a través del tiempo, y termina por dificultar la adaptación a nuevos modelos de la expansión.

Para analizar estas problemáticas, las páginas que siguen se centran en las Memorias del Departamento Topográfico de la Provincia de Buenos Aires, en los debates legislativos (1910-1913) que trataron el proyecto de ley de formación de pueblos y ejidos, en su decreto reglamentario (1927) y en el relevamiento realizado en el Departamento de Investigación Histórica Cartográfica de la Dirección de Geodesia del Ministerio de Obras Públicas de la Provincia de Buenos Aires, sobre un total de ochenta y dos (82) barrios parque. El desarrollo del artículo se organiza en tres segmentos: en el primero se presenta una pintura amplia que permite comprender el contexto en el que se dieron los debates y procesos de expansión de la ciudad. En el segundo se analizan las formas de "hacer ciudad" instaladas desde la normativa, para considerar en el tercer segmento, algunos casos que permiten analizar la articulación entre las normas y las formas concretas del crecimiento territorial.

\section{El proceso expansivo}

En líneas generales, es posible reconocer que en la base del crecimiento de los suburbios residenciales modernos se encontraban inscriptos procesos de modernización técnicos, culturales y sociales iniciados en las últimas décadas del siglo XIX. En efecto, la ampliación de las redes ferroviarias y camineras, la difusión de las tendencias higienistas, la incorporación de pautas de sociabilidad vinculadas al sporty al uso del tiempo libre, la transformación de los modos y modelos de habitar, así como los procesos de ascenso económico, potenciados a su vez por los procesos de metropolización que sufrió la ciudad de Buenos Aires a comienzos del siglo XX, llevaron a que algunos sectores sociales intentaran compensar las características de la vida urbana con el refugio en sitios aislados ${ }^{4}$.

Este proceso debe ser considerado como parte del ciclo expansivo de Buenos Aires, que tuvo lugar entre 1887 y 1970 y dentro del cual se reconocen dos subperíodos, con dos lógicas de crecimiento muy diferentes (Torres, 1975; Gorelik, 2009) ${ }^{5}$. La primera expansión, formada entre 1887 y 1938, es tributaria del gran crecimiento poblacional marcado por la fuerte presencia de inmigración europea. En esta etapa se desarrolló una corona de barrios periféricos dentro del área de la Capital, ligada a procesos de ascenso social de los sectores populares (artesanos y obreros inmigrantes, pequeños comerciantes inmigrantes o criollos, profesionales y burócratas criollos) que a través de loteos económicos lograron acceder a la vivienda propia. A diferencia de lo que sucederá en el Gran Buenos Aires, estos loteos se materializaron a partir de una grilla pública extendida, hacia fines del siglo XIX, no sólo a la ciudad existente, sino previendo el crecimiento futuro. De acuerdo a Gorelik (1998) esta base homogénea generó en la ciudad de Buenos Aires la posibilidad de una integración social y cultural, que evitaría la formación de una periferia como un patchwork de alto contraste entre "barrios altos" y arrabales miserables. Sin embargo, la definición de este proceso solo puede aplicarse a la expansión ocurrida dentro del área de la Capital.

La segunda periferia se organizó por fuera de los límites de la ciudad de Buenos Aires, precisamente en el momento en que estos se materializaban a partir de la construcción de la avenida de circunvalación General Paz (1936-1941).

En esta segunda expansión, el crecimiento suburbano se materializó a través de la emergencia de

4 En relación al concepto de "metropolización” ver: Simmel (1986). Para el caso argentino tomamos a Gorelik (1998).

5 Recordemos que en 1880, bajo la presidencia de Julio Argentino Roca, tuvo lugar la separación de la Ciudad de Buenos Aires de la provincia de Buenos Aires. Este cambio supuso la pérdida de la provincia de su capital y principal centro urbano, político, cultural, social y financiero (sobre estos temas, véase: Hora, 2001; Míguez, 2013). 


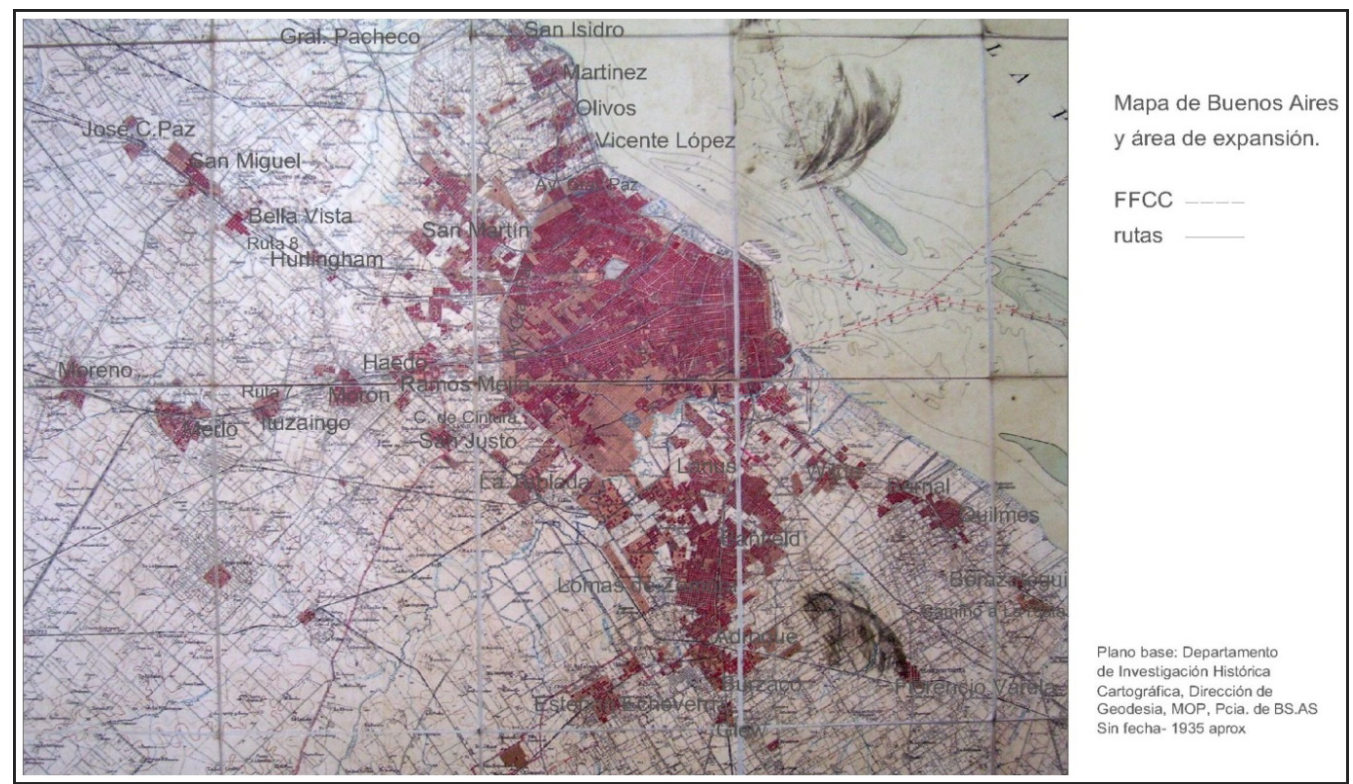

Figura 1 - Mapa de Buenos Aires y Área de Expansión. Circa 1935

Fuente: Departamento de Investigación Histórica Cartográfica, Dirección de Geodesia MOP, Provincia de Buenos Aires.

operaciones en torno a nuevas estaciones ferroviarias junto a una densificación de los núcleos que existían con anterioridad (Gómez Pintus, 2014) (Figura 1). Pocos años más tarde, el rápido desarrollo del mercado inmobiliario, impulsado por lo que se vivía como un proceso de expansión inagotable de la ciudad y de los medios técnicos que lo propiciaban, hizo posible, además de la revalorización de antiguos pueblos y la consolidación de manzanas y vacíos intersticiales en áreas ya pobladas, considerar la creación de núcleos suburbanos para el establecimiento de quintas o residencias de fin de semana en algunos sentidos de la expansión. Justamente, durante la década del treinta cuando las lógicas de ocupación del suelo dictadas por el ferrocarril empezaron a quebrarse por la ampliación de la red caminera, se asistió por un lado, a la incorporación de loteos de dimensiones menores que se anexaron a aglomeraciones de cierta importancia y, por otra parte, a loteos de grandes dimensiones ubicados sobre las rutas intersticiales que jugaron un rol fundamental para guiar nuevos sectores de la expansión (Figura 2) ${ }^{7}$.

6 Para un estudio en profundidad de los procesos de crecimiento del área metropolitana de Buenos Aires, véase: Torres (1993); Sargent (1974).

7 La década del treinta marcó el paso del ferrocarril al automóvil. En 1932 se sancionó la Ley nacional de Vialidad № 11.658 que dio origen a la Dirección Nacional de Vialidad (DNV),
Ahora bien, concentrémonos por un momento en el cómo, es decir, en el modo en que se gestaron estos procesos de urbanización y en las características particulares que los definieron.

Desde fines del siglo XIX, ante la expansión de la ciudad y el posible crecimiento de la demanda de tierras, comenzaron los loteos y subdivisiones de las viejas quintas y áreas rurales. A medida que los valores subían se iniciaba la tendencia de algunos sectores a invertir en tierras.

Sobre el valor de la tierra suburbana -loteada y ofrecida como tierra prometida- se cargaba el costo del loteo, la promoción de las ventas, la publicidad, y aún más, la tendencia especulativa de los primeros compradores que querían repetir el negocio. (Romero, 2009, p. 276).

En el escenario latinoamericano, estos procesos dieron lugar a un denominador común que compartieron las áreas metropolitanas: su condición de urbanización por fragmentos. Teniendo en cuenta que la tierra

decisiva para la extensión y modernización de la red vial. A la vez, esta ley puede entenderse como expresión de la actitud modernizadora que emprendía el Estado Nacional (Ballent $\&$ Gorelik, 2001). Cabe recordar que la ley determinaba que las provincias, para tener acceso a la ayuda federal, debían crear y organizar sus propias direcciones de vialidad. A razón de esta norma, en 1936 fue creada la Dirección de Vialidad de la Provincia de Buenos Aires. 


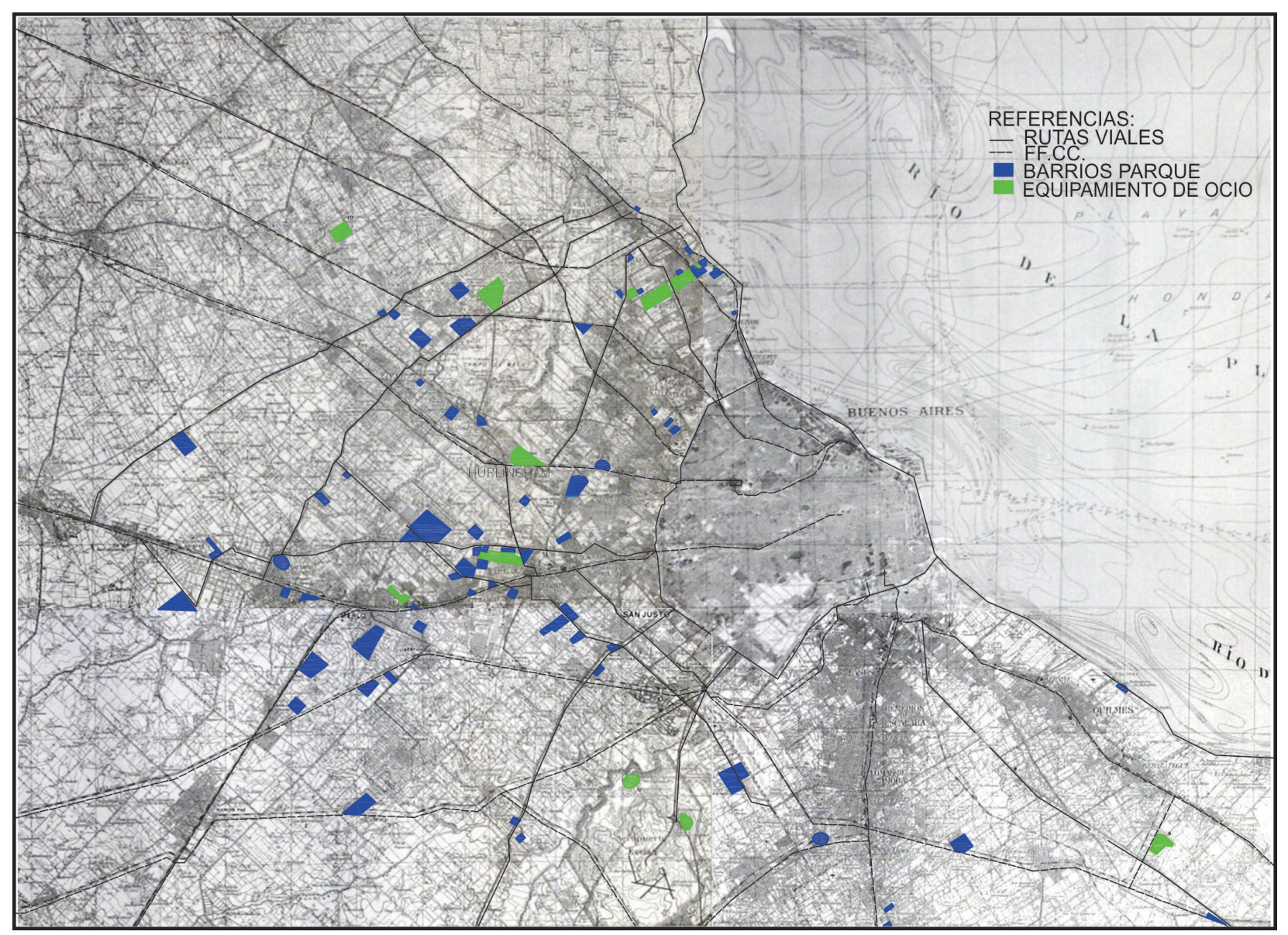

Figura 2 - Urbanizaciones de Barrios Parque 1910-1950

Fuente: Elaboración propia a partir de la Carta Topográfica del Instituto Geográfico Nacional (1945) y datos relevados del Departamento de Investigación Histórica Cartográfica de la Dirección de Geodesia del Ministerio de Obras Públicas de la Provincia de Buenos Aires.

suburbana pertenecía en su mayor parte a sectores privados, podemos entender que las ciudades se hayan construido básicamente a partir del cruce de intereses, entre los agentes actuantes dentro de las lógicas del mercado y las acciones del Estado tendientes a regularlo. En cuanto a éstas últimas, las regulaciones establecieron - en la mayoría de los países - restricciones relacionadas con la morfología, mientras que, prácticamente no existieron restricciones para que la tierra rural sea transformada en urbana.

En Argentina, cualquier tierra de uso rural cuyo propietario decidiera convertirla en tierra urbana, podía hacerlo (Clichevsky, 1975). En la práctica, esto implicó que a partir de un trámite administrativo una porción de tierras rurales se convertía en urbana, de modo que podía ser loteada en fracciones menores y vendidas para uso residencial, independientemente del mejoramiento en las condiciones de accesibilidad, infraestructuras, etc. En el escenario que iba conformándose convivían enormes cantidades de tierras vacantes ${ }^{8}$ - muchas de ellas dotadas de equipamientos y de servicios - entre áreas loteadas y urbanizadas con anterioridad, mientras que una

8 La definición de tierras vacantes no es exactamente la misma para todos los países de Latinoamérica. Esto depende, fundamentalmente, de los límites que se reconozcan como parte del área urbana o metropolitana. Para el área de Buenos Aires se reconoce como tierra vacante a la tierra privada no utilizada que se encuentra subdividida en parcelas denominadas "urbanas" dentro del perímetro de la aglomeración. Así como a la tierra de propiedad fiscal que ha sido desafectada de sus anteriores usos. Esta es la definición ha sido propuesta por Clichevsky (1975), y a partir de la misma se obtuvieron los datos que en este artículo citamos. 
enorme cantidad de población quedaba relegada a áreas lejanas desprovistas de estos mismos servicios y de equipamientos elementales ${ }^{9}$.

Por otra parte, la cantidad y dimensión de los vacíos era sumamente heterogénea dentro de los diferentes sectores urbanos. Esto dependía de las formas de crecimiento particular que hubieran tenido los mismos, los tipos de propietarios, los usos según las demandas, las expectativas no concretadas de localización de actividades productivas y las obras públicas realizadas. A lo largo del proceso de expansión, estas áreas quedaron reducidas, mayoritariamente, a las zonas periféricas de los ejes de la expansión de las ciudades y en menor magnitud, a las áreas centrales intersticiales. En el caso de Buenos Aires, las escasas restricciones impuestas para la producción de tierra urbana, de la mano de las importantes ganancias que las subdivisiones prometían, redundó en una enorme cantidad de áreas subdivididas y no loteadas (en espera de un crecimiento de la demanda y de los valores) y de muchas otras, loteadas y vendidas sólo parcialmente. El área metropolitana de esta misma ciudad poseía para la década del setenta -momento a partir del cual se cuenta con datos más globalesimportantes porcentajes de áreas vacantes ${ }^{10}$. Según los datos propuestos por Clichevsky (2002) en Sudamérica sólo la superaba Río de Janeiro, donde las áreas vacías comprendían el 44\% de la superficie del Municipio; le seguía Buenos Aires con el 32\%, y

9 En ocasión de las reuniones de Municipios del GBA (La Plata, 8 de octubre de 1948), el concejal Ferrari de Lomas de Zamora expresó: “[...] desgraciadamente tenemos nosotros centenares y centenares de lotes baldíos, dotados de agua corriente, luz eléctrica, medios de transporte, y como los mismos no se venden, tenemos que mandar a nuestros compañeros obreros a construir viviendas a 10 o $15 \mathrm{~km}$ del centro de sus actividades, porque allí es donde se hacen los remates en abundancia, mientras que dentro de la planta urbana, donde se cuenta con todos los servicios públicos y con los elementos de primera necesidad, hay cantidad de lotes que nadie los puede ocupar porque sus propietarios no los sacan a la venta, con el propósito de especular con ellos". (Zamora apud Pastor \& Bonilla, 1958, p. 178).

${ }^{10}$ Existen algunos datos más específicos que los que aquí mencionamos y que pertenecen a investigaciones particulares realizadas sobre diferentes municipios. Se ha optado por no incorporar estos datos ya que cubren cuestiones muy parciales en relación a nuestra investigación. Para profundizar en el tema, véase: Bevilacqua de Cristino (1993) y Clichevsky et al. (1990). por debajo quedaban Quito, con el 21,7\% del suelo urbano vacante y Lima donde la tierra vacante se estimaba en el $10 \%$.

Si realizamos un zoom sobre los barrios que aquí analizamos, el proceso de urbanización implicado debe entenderse como espontáneo (en tanto no es resultado de un proceso centralizado de planificación urbana) y privado (en cuanto fueron los dueños de la tierra, promotores y loteadores quienes llevaron adelante el proceso) ${ }^{11}$. Dentro de esta lógica, los emprendimientos se organizaron a partir de tres fases. La primera, de subdivisión y loteo de tierras. La segunda, de producción de vivienda individual a cargo de los nuevos propietarios, que construyeron sus unidades lentamente, o que muchas veces mantuvieron los lotes vacantes en espera de una futura valorización para su reventa. Y la tercera, correspondiente a la incorporación de infraestructura (urbanización de las calles, tendido de redes públicas de servicios, etc.) a cargo de los poderes locales.

En líneas generales, es posible señalar que se repite a menor escala el mismo proceso de urbanización que describimos para el Gran Buenos Aires. En efecto, se asiste a un proceso de urbanización lento y fragmentario, dado que los diversos agentes actuaron con cierta independencia en la localización de sus construcciones, en los ritmos de su ejecución, en los volúmenes y las tipologías edificatorias. Un conjunto de pequeñas decisiones, la mayoría privadas, dio forma a las urbanizaciones con resultados diversos según las áreas de la expansión, los sectores sociales a quienes fueran destinadas, etc.

\section{Estado y regulación territorial: debates en torno al proyecto de ley de fundación de pueblos y contenidos de la misma}

En este punto, enfocamos la investigación hacia el núcleo de las políticas públicas y los marcos regulatorios impulsados por el Estado provincial. En este contexto, cabe resaltar que los barrios a los que nos referimos quedaron enmarcados en la ley de "fundación de pueblos" sancionada en 1913. Con unas pocas reglamentaciones, la ley establecía los procedimientos a seguir para la presentación y

\footnotetext{
${ }^{11}$ Un estudio particular sobre los actores que intervinieron en los procesos de producción del suelo urbano, puede verse en Gómez Pintus (2013).
} 
aprobación de los trazados y algunos requisitos en relación a cuestiones morfológicas: se establecían anchos mínimos para calles y avenidas, de $15 \mathrm{mts}$ y $20 \mathrm{mts}$ respectivamente; se establecían los porcentajes de superficie que los propietarios debían ceder para uso público y, en cambio, resultaban ausentes las referencias al posible destino y uso de las tierras.

Esta ley había comenzado a discutirse en julio de 1910 cuando el senador conservador Eduardo Arana (que entre otras cuestiones durante su actuación en la arena política había impulsado la creación de los partidos de Roque Pérez y Esteban Echeverría) presentó en la Cámara Alta un proyecto cuyo objetivo era reglamentar la fundación de pueblos y villas en la provincia. Los fundamentos esgrimidos por Arana se centraban en el hecho de que la provincia no tenía tierras para dividir y la acción particular suplía esa necesidad "guiada generalmente por una idea de especulación." Desde la perspectiva del senador, muchos pueblos eran fundados en terrenos inadecuados lo que plantearía, a futuro, numerosos problemas como ocurría en La Boca (Ciudad de Buenos Aires). El proyecto establecía una serie de mecanismos institucionales de control y aprobación de los terrenos sobre los cuales se fundarían los pueblos o villas, y que evitarían inconvenientes de diversas índoles.

Para ello, la mensura y los planos del predio a enajenarse, al igual que la división y subdivisión que se intentara dar, debían estar aprobados por los cuerpos técnicos del Ministerio de Obras Públicas de la Provincia. Una vez que estos dieran el visto bueno, el Poder Ejecutivo remitiría nuevamente a consideración de dos organismos estatales - el Departamento de Ingenieros y a la Dirección de Salubridad - las condiciones topográficas de altura, los desagües de tierras y la potabilidad del agua para consumo (Buenos Aires, 1913a, p. 293). Pese a la existencia de informes técnicos, el proyecto le otorgaba al Poder Ejecutivo la facultad de acordar o denegar los permisos para la fundación de un pueblo ${ }^{12}$.

\footnotetext{
${ }^{12}$ Estas atribuciones concedidas al Poder Ejecutivo fueron debatidas en las sesiones que trataron el proyecto de ley en mayo de 1913. El senador Barros consideraba que la aprobación definitiva de la fundación o no de un pueblo debía correr por cuenta de los cuerpos técnicos y el Poder Ejecutivo sólo debía limitarse a aprobar lo que estos señalaran ya que, desde su perspectiva, "[...] el Poder Ejecutivo no es otra cosa que un compuesto de un jefe y de muchos empleados que lo asesoran." (Buenos Aires, 1913a, p. 88-89). La propuesta de
}

En agosto de 1911, el proyecto fue tratado nuevamente en Senadores, pero recién en junio de 1913, bajo el gobierno interino de Arana, se sancionó la ley N $\mathrm{N}^{\circ} 3487$ denominada "Fundación de pueblos" - vigente hasta 1977 (Buenos Aires, 1913b) - que logró producir un marco más general para las nuevas delineaciones.

Los debates legislativos en torno al proyecto, del mismo modo que la letra de la ley, permiten observar algunas cuestiones. En primer lugar, en términos teóricos, observamos una cierta capacidad de los actores estatales para construir un problema, instalarlo en la agenda pública y, finalmente, discutir y formular las políticas tendientes a darle solución. Ahora bien, como nos recuerda la literatura en administración pública, las políticas tienen un ciclo que no se reduce a su elaboración, sino también a su implementación y posterior evaluación sobre estrategias para evitar "desvíos o incumplimientos"13. En tal sentido, si nos ajustamos al modelo antes mencionado, se observa una mayor capacidad del Estado provincial para completar las primeras fases del ciclo de las políticas públicas: construcción de agenda, formulación de la política y proceso de decisión. Pero, como veremos más adelante, registramos una menor capacidad del aparato estatal provincial para cumplir con las últimas fases (implementación y evaluación).

En segundo lugar, la formulación y sanción de la ley nos permite examinar dos cuestiones, teniendo en cuenta que el proceso que analizamos implicó la adecuación de los agentes privados a una nueva normativa de carácter obligatoria impuesta por el Estado provincial. Por un lado, observamos el vínculo entre el Estado y los intereses particulares; por el otro, un contraste entre las normas y las prácticas. Con respecto a la primera, como señalamos anteriormente, la ley establecía algunas características morfológicas que debían presentar la fundación de un pueblo o la ampliación de un ejido. Sin embargo, no se fijó el posible destino y uso de las tierras. La ausencia de este aspecto puede dar cuenta de aspectos un

Barros no fue tenida en cuenta, pero expresa la existencia de una tensión entre la esfera técnica y la esfera política, frecuente en la construcción de políticas públicas.

13 Nos basamos en el clásico modelo del ciclo de las políticas públicas: Agenda pública - Formulación de política - Proceso de decisión - Implemetación - Evaluación. Sobre estos temas, véase: Oszlak \& O’Donnell (1984); Oszlak (2006); Aguilar Villanueva (1993); Rein \& Rabinovitz (1993); Van Meter \& Van Horn (1993), entre otros. 
poco más complejos. Hacer una ley que regulara el comportamiento de actores privados no implica ni niega que estos no hayan tenido alguna influencia explícita o implícita, en definitiva, la propia ley los proponía como principales destinatarios. En tal sentido, nos alejamos de la propuesta de Skocpol que destaca la autonomía del Estado - en tanto consideramos que esta se constituye como tipo ideal o concepto de utilidad más bien metodológica - y recordamos que, como ha señalado Mann (1991) no es posible pensar un Estado "puro" completamente aislado de grupos sociales o privados. Asimismo, Bourdieu \& Wacquant (2005), desde una perspectiva teórica y analítica diferente, han destacado los modos en que los agentes privados ayudan a orientar las políticas estatales.

Sobre la segunda cuestión señalada, nos preguntamos por qué, a pesar de la norma, ciertas prácticas pervivieron. Se trata de entender que las prácticas no desaparecen mágica ni automáticamente porque una ley establezca otros criterios. Las prácticas y las normas recorren senderos diferentes, y pensar que el contraste entre ellas sólo reside en que algunas normas son infringidas es limitar la interpretación de la naturaleza del problema. En todo caso, y como presentaremos más adelante en relación directa a algunos casos, hay mayores o menores adecuaciones a la ley, dependientes de determinados contextos, tradiciones y procesos, y de un conjunto de situaciones, relaciones y entramados subyacentes, escenarios que no siempre los legisladores pueden "leer", entrever o prever ${ }^{14}$.

\footnotetext{
${ }^{14}$ Un ejemplo de las dificultades entre la ley y su puesta en práctica queda en evidencia en los debates legislativos de 1922, que tenían como objetivo destinar parte de un empréstito para ampliación de ejidos. En este marco, los senadores dieron cuenta de las dificultades de aplicación de la ley de 1913. En efecto, legisladores de todas las fuerzas políticas destacaron que la ley de 1913 era "muy buena" si se aplicaba estrictamente; Martínez Sosa señaló: “[...] en la práctica ha fracasado, por cuanto no tengo conocimiento de que en los diez años de vigencia, se haya acogido ninguna municipalidad [...] no la encontraron conveniente." El senador radical Fauzón precisó que el problema de la ley residía en que la cantidad de hectáreas autorizadas para ampliar los ejidos era muy reducida y solo podía servir para pueblos que recién se fundaban. En respuesta, De Miguel (también miembro del Partido Radical) destacó que el inconveniente máximo no era tal, sino que los municipios desconocían la existencia de esta ley, lo que motivaba a que las autoridades comunales concurrieran a la cámara "pidiendo leyes ampliatorias de sus ejidos" (Buenos Aires, 1922, p. 743-744). En definitiva, los distintos sectores
}

Por último, los debates legislativos nos permiten examinar los alcances y límites de la "razón técnica" frente a las decisiones políticas. Como suele ocurrir con aquellas políticas o acciones que afectan de un modo u otro al territorio, la esfera técnica posee un margen de maniobra menor frente a las necesidades e intereses políticos o partidarios. Sin embargo, si en el proceso de toma de decisiones primaba la política (es decir, si la política en última instancia "decidía") podía hacerlo porque existía una base técnica que lo sustentaba. En otras palabras, el propio juego político también encontraba limitaciones que constituían el terreno de la técnica y le permitían a esta imponer sus saberes sobre el territorio. En efecto, los cuerpos que integraban el Ministerio de Obras Públicas de la Provincia eran los encargados de otorgar permisos a los propietarios de los terrenos destinados a la formación de los pueblos y también de elaborar los informes técnicos (trazados, condiciones topográficas y desagües de la tierra) que luego serían aprobados o no por el Poder Ejecutivo. En algún sentido se trataba más de amalgamar y complementar dos esferas que no siempre conviven en tensión o en conflicto, ya que como destaca Camou (1997) en las sociedades complejas toda cuestión "técnica" importante conlleva cuestiones de "política" y, viceversa, de modo tal que cuestiones "técnicas" y cuestiones "políticas" son "como dos puntas de un mismo ovillo."

Este fue el marco legal bajo el cual fueron trazados los primeros barrios que analizamos. La reglamentación de la ley de 1913 llegó recién en octubre de 1927, cuando el gobierno del radical Valentín Vergara consideró pertinente establecer disposiciones para los propietarios de terrenos e instrucciones generales para los ingenieros y agrimensores encargados de practicar el trazado de los centros de población (Buenos Aires, 1927). No contamos con datos certeros que revelen los intereses del gobierno de Vergara por reglamentar esta ley, sin embargo, la aprobación de planos de diversos pueblos (como General Alvarado y Tigre) y las solicitudes de ampliación de ejidos presentados por autoridades comunales a la Legislatura nos proveen de algunos indicios ${ }^{15}$. Recordemos que el Estado

políticos solicitaban la modificación y difusión de la ley de 1913, dado que la consideraban insuficiente para cubrir las necesidades reales de los municipios.

15 Bajo la administración de Vergara se resolvió ampliar los ejidos de Necochea, Arenales, Suipacha, Capitán Sarmiento, Pueblo Vacarezza, Las Flores, Navarro, Ameghino, González Cháves, Balcarce y Monte (Barba \& DemaríaMassey, 1987). 
de los años veinte había ampliado sus márgenes de intervención en cuestiones políticas y sociales, lo cual nos lleva a inferir que frente a demandas de poderes locales y particulares vinculadas a la expansión del territorio (nuevos pueblos y ensanche de ejidos) actuó en igual sentido, interviniendo indirectamente a través del establecimiento de más pautas de ordenamiento territorial. No obstante, a pesar del cambio de signo político entre las gestiones que sancionaron la ley (conservadora) y la reglamentación (radical) esta última no modificó sustancialmente a la primera sino que la complementó, registrándose una continuidad entre ambas.

Pero, ¿cuáles fueron las particularidades del decreto reglamentario? Como señalamos anteriormente, este decreto estableció de modo más detallado la forma de procedimiento que debían observar los propietarios para la fundación o ampliación de pueblos. De este modo, se imponían nuevas cuestiones en relación al trazado, medidas mínimas del loteo, orientación de calles y avenidas y, aunque seguía sin reglamentarse una división de usos del suelo, se reconocían diferentes tipos de parcelamiento: para la planta urbana, para quintas $y$, finalmente, chacras $^{16}$.

En cada uno de estos casos se establecía que cada manzana debía estar limitada por calles en todos sus costados.

a- Dentro de la planta urbana las manzanas no podían superar los $150 \mathrm{mts}$ de frente, y los solares que la conformaban debían poseer al menos $10 \mathrm{mts}$ de frente - recién en 1949, cuando se reglamenten legalmente los barrios parque, los lotes que lo compongan deberán presentar frentes mínimos de $20 \mathrm{mts}$. b- En la zona de quintas, que debe trazarse a continuación de las manzanas: 1-"cada quinta debe estar rodeada de calles en relación con el trazado del pueblo, y su superficie no debe superar las 11 hectáreas.

\footnotetext{
${ }^{16}$ La división de usos del suelo, es decir, del tipo de actividades (residencial, comercial, industrial) que pueden instalarse en determinado sector de la ciudad es una de las herramientas más utilizadas por el planeamiento urbano moderno para controlar las formas de crecimiento urbano. El documento conocido como Zoning Resolution de 1916 para New York se considera como uno de los primeros instrumentos en utilizar ampliamente la zonificación de los usos del suelo, sin embargo, tanto en ese país como en Alemania ya se habían hecho algunos avances hacia los años 1880. Sobre estos temas, véase: Hall (1996).
}

2- "las quintas tendrán las dimensiones que correspondan para contener varias manzanas del pueblo, de manera que en un futuro se pueda realizar la división en manzanas." 3- "es facultativo dividir las quintas en fracciones de quintas; donde cada fracción debe tener frente a la vía pública." c- Finalmente para las chacras se establecen iguales condiciones que para las quintas, es decir, que: "deben contener quintas regulares capaces de subdivisión y trazado de calles" y "pueden fraccionarse, teniendo cada fracción frente a la vía pública." (Buenos Aires, 1927).

Además del carácter general de la ley y de su reglamentación, se observa que particularmente en relación al parcelamiento -es decir, la subdivisión de la tierra en lotes, manzanas, etc- la cuestión se abordó desde la lógica urbana y más específicamente, desde la tradición regularizadora de la cuadrícula instalada durante la colonización y mantenida como base para los trazados a lo largo de todo el siglo XIX. Recuérdese también la extensión de una grilla homogeneizadora sobre la Capital Federal ${ }^{17}$. Sin embargo, la figura tradicional de centro de poblado y áreas periféricas que la tradición regularizadora contribuyó a instalar, como puede verse en el pueblo de Morón (Figura 3), era difícilmente aplicable al fenómeno que estaba teniendo lugar en el área metropolitana ${ }^{18}$. En este punto - como demostramos en la introducción- nos encontramos, por un lado, frente a la lógica del crecimiento concéntrico con su núcleo en la Capital

${ }^{17}$ En paralelo a la formación de los órganos e instituciones encargados de establecer, reglamentar y producir las normas de ordenamiento del territorio bonaerense, empezaba a articularse una noción que sintetiza, tal vez mejor que ninguna otra, la naturaleza de las transformaciones del siglo XIX.

18 Nos referimos a la noción de "regularidad". Como bien han estudiado Fernando Aliata (2006) y Graciela Favelukes (2011), en este término podían reconocerse los lineamientos del paradigma notarial, instalado en el siglo XVIII, basado en la regularidad legal y que a partir del período rivadaviano comenzó a asociarse a la noción de orden que busca instalarse en el plano urbano, superándolo. Se supone que el orden regular construido en el territorio repercutirá favorablemente sobre el orden social. Es decir, una figura regular provocará indefectiblemente regularidad en aquellos que estén sujetos a ellay, por lo tanto, una mejora sustancial en su comportamiento. 


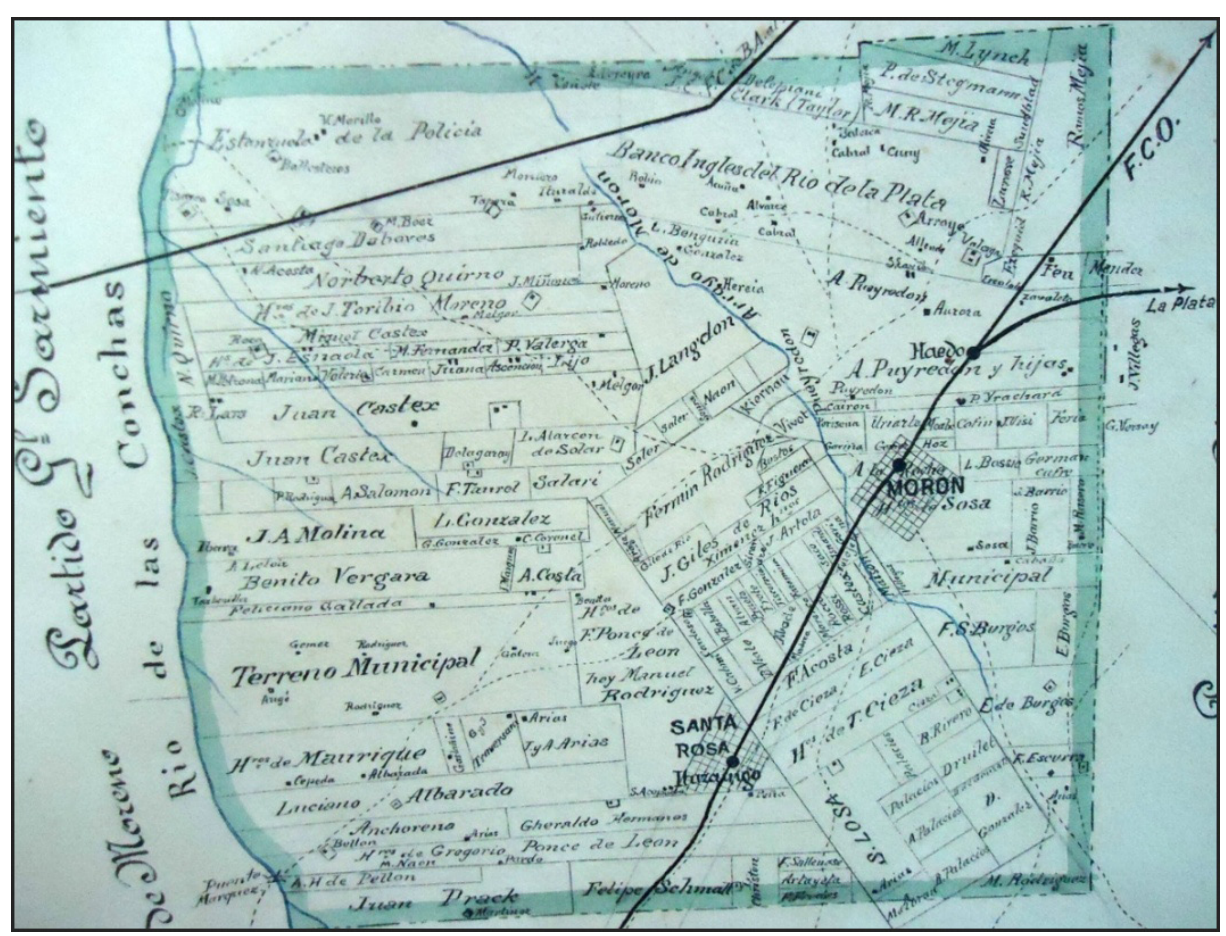

Figura 3 - Plano del Partido de Morón. Registro gráfico de propiedades rurales y eijdo de los pueblos de campaña. Circa 1860

Fuente: Departamento de Investigación Histórica Cartográfica de la Dirección de Geodesia del Ministerio de Obras Públicas de la Provincia de Buenos Aires.

que expandía sus brazos sobre el área metropolitanay, por otro, superponiéndose a estos brazos, se reconocía un panorama de tramas, en relación a los diversos núcleos, que se cruzaban y superponían ante la falta de un trazado homogeneizador que, al menos en la gran escala, permitiera entender las intervenciones como parte de un todo coherente.

A pesar de que Adrián Gorelik (1998) destacó el consenso que existía a fines del siglo XIX respecto a la valoración negativa sobre la cuadrícula, incluso entre los técnicos de los equipos municipales, nuestro análisis revela que, en la práctica, la pervivencia de códigos y reglamentaciones que, como demostramos, seguían rigiéndose por esa lógica, no hacía más que dificultar la puesta en marcha y el quiebre con la tradición regularizadora de antaño. Lo que persistía a través de las reglamentaciones eran una serie de supuestos sobre los cuales no se discutía: continuidad, regularidad, homogeneidad, integración ${ }^{19}$. En síntesis, nuevamente es posible observar una carencia de armonía

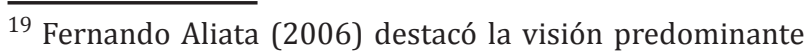
durante el siglo XIX, de aplicar figuras simples para organizar un espacio determinado, donde se buscaba la continuidad y repetición de elementos a fin de que el orden a establecer sea lo más sencillo posible. entre lo normativo (las leyes y reglamentaciones) y las prácticas (aquello que, en definitiva, se hacía).

\section{La aplicación de los códigos, reglamentaciones y su adecuación a las problemáticas preexistentes en la expansión}

En este punto, es necesario presentar el desfase entre norma y práctica de manera concreta, y ver de qué forma se articularon los loteos (ver Cuadro 1) con la reglamentación existente. Una revisión sobre algunos de los emprendimientos llevados a cabo durante el período permite ilustrar este razonamiento.

El primer núcleo problemático que se establece responde a lo que podríamos denominar "la extemporaneidad": entendemos que las reglamentaciones vigentes fueron pensadas para aplicarse en operaciones de grandes dimensiones. Según indicaba el decreto reglamentario de 1927, se proponía para la organización del trazado la subdivisión en planta urbana, quintas y chacras. Esta disposición había sido pensada por los actores intervinientes teniendo en cuenta una futura expansión y el establecimiento de núcleos poblacionales incipientes, es decir, se pensaba en un momento fundacional, en el que el terreno estaría 
Cuadro 1 - Relevamiento de loteos de tipo barrio parque entre 1910-1950

(continua)

\begin{tabular}{|c|c|c|c|c|c|c|c|c|c|}
\hline & Partido & Núcleo & $\begin{array}{l}\text { Cantidad de } \\
\text { parcelas }\end{array}$ & $\begin{array}{c}\text { Superficie } \\
\text { de la parcela } \\
\text { (en } \mathrm{m} \text { ) }\end{array}$ & $\begin{array}{c}\text { Dimensión } \\
\text { del núcleo } \\
\text { (en ha) }\end{array}$ & $\begin{array}{c}\text { valor } \\
\text { economico } \\
\text { de la parcela } \\
(\text { en } \$ \text { ) } \times \text { mes }\end{array}$ & $\begin{array}{c}\text { Año de } \\
\text { realización } \\
\text { del ler loteo }\end{array}$ & Tipología & $\begin{array}{l}\text { distancia a } \\
\text { la Capital }\end{array}$ \\
\hline 1 & Alte. Brown & B. P. Manuel Obligado & 2.000 & 400 & 80 & $\$ 5$ & 1929 & C.N.P. & 22 \\
\hline 2 & Alte. Brown & B.P. Burzaco & 100 & 300 & 3 & $\$ 10$ & $s / d$ & L.S. & 25 \\
\hline 3 & Alte. Brown & La Carmen Bonorino & 65 & 900 & 5,85 & $\$ 10$ & 1947 & $P . P$ & 26 \\
\hline 4 & Boulogne & Gral. Urquiza & 416 & 500 & 20,8 & $\$ 8$ & 1946 & L.S. & 28 \\
\hline 5 & G.Sarmiento & B.P.Mattaldi & 700 & 400 & 28 & $\$ 10$ & 1926 & L.S. & 20 \\
\hline 6 & G.Sarmiento & B.P. Santa Mónica & 113 & 1.000 & 11,3 & $\$ 15$ & 1946 & $P . P$ & 21 \\
\hline 7 & G.Sarmiento & B.P.San Andrés & 200 & 500 & 10 & $\$ 7$ & 1931 & N.E & 15 \\
\hline 8 & G.Sarmiento & B.P.La Primavera & 200 & 800 & 16 & & 1946 & L.S. & 34 \\
\hline 9 & G.Sarmiento & B.P. La Huella & 109 & 800 & 8,72 & $\$ 15$ & 1947 & L.S. & 30 \\
\hline 10 & G.Sarmiento & Quintas San Miguel & 133 & 900 & 11,97 & $\$ 10$ & 1940 & L.S. & 32 \\
\hline 11 & G.Sarmiento & B.P. Bellaflor & 80 & 700 & 5,6 & & 1944 & P.P & 30 \\
\hline 12 & Gral.San Martín & Villa Zagala & 200 & 400 & 8 & $\$ 4$ & 1936 & P.P & 12 \\
\hline 13 & La Matanza & Puente Ezcurra & 700 & 400 & 28 & $\$ 7$ & 1948 & & 18 \\
\hline 14 & La Matanza & Golden Park & & 800 & 0 & $\$ 35$ & 1949 & L.S. & 25 \\
\hline 15 & La Matanza & B.P. Gral. San Martín & 134 & 900 & 12,06 & $\$ 10$ & 1945 & L.S. & 23 \\
\hline 16 & La Matanza & B.P. Peluffo & 400 & 1.000 & 40 & $\$ 50$ & 1945 & L.S. & 23 \\
\hline 17 & La Matanza & Parque Ibañez & 400 & 1.800 & 72 & & 1947 & L.S. & 20 \\
\hline 18 & La Matanza & B.P. Santa Clara & 100 & 1.500 & 15 & $\$ 20$ & 1945 & L.S. & 18 \\
\hline 19 & La Matanza & El Pino & 0 & 0 & 0 & $\$ 30$ & 1950 & & 24 \\
\hline 20 & La Matanza & Santa Amelia & 270 & 350 & 9,45 & $\$ 30$ & 1945 & & 22 \\
\hline 21 & La Matanza & La Ganga & 31 & 400 & 1,24 & $\$ 0$ & 1947 & $P . P$ & 25 \\
\hline 22 & La Matanza & Camping Club & 150 & 900 & 13,5 & & & P.P & \\
\hline 23 & Lomas de Zamora & B.P. Lavallol & 600 & 400 & 24 & $\$ 10$ & 1933 & N.E & 31 \\
\hline 24 & Lomas de Zamora & Las Torres & 270 & 900 & 24,3 & $\$ 30$ & 1949 & & 30 \\
\hline 25 & Lomas de Zamora & Lomas de Beheran & & 1.200 & & $\$ 60$ & 1948 & L.S. & 30 \\
\hline 26 & Lomas de Zamora & San Juan de Biocca & 438 & 800 & 35,04 & $\$ 6$ & 1948 & $P . P$ & \\
\hline 27 & Merlo & Gran.B.P.San Martín & 5.000 & 400 & 200 & $\$ 15$ & 1949 & C.N.P. & 35 \\
\hline 28 & Merlo & El Pericón & 300 & 300 & 9 & $\$ 15$ & 1950 & L.S. & 33 \\
\hline 29 & Merlo & La Esmeralda & 300 & 800 & 24 & $\$ 70$ & 1949 & $P . P$ & 34 \\
\hline 30 & Merlo & Est. Agustín Ferrari & 2.000 & 800 & 160 & $\$ 20$ & 1950 & N.E & 37 \\
\hline 31 & Merlo & Paso del Rey & 800 & 600 & 48 & $\$ 20$ & 1947 & C.N.P. & 33 \\
\hline 32 & Merlo & B.P. Gral. Alvear & 130 & 1.000 & 13 & $\$ 20$ & 1946 & L.S. & 28 \\
\hline 33 & Merlo & B.P. Los Indios & 100 & 800 & 8 & & 1946 & L.S. & 30 \\
\hline 34 & Merlo & B. Golf Ituzaingo & 300 & 400 & 12 & $\$ 10$ & 1932 & C.N.P. & 27 \\
\hline 35 & Merlo & B.P. San Antonio & 140 & 800 & 11,2 & $\$ 16$ & 1945 & $P . P$ & 32 \\
\hline 36 & Merlo & La Teja & 450 & 1.200 & 54 & $\$ 15$ & 1947 & L.S. & 35 \\
\hline
\end{tabular}

Fuente: Elaboración propia a partir de datos del Departamento de Investigación Historíca Cartográfica de la Dirección de Geodesia del Ministerio de Obras Públicas de la Provincia de Buenos Aires.

urbe. Revista Brasileira de Gestão Urbana (Brazilian Journal of Urban Management), 2016 maio/ago., 8(2), 242-260 
Cuadro 1 - Relevamiento de loteos de tipo barrio parque entre 1910-1950

(continua)

\begin{tabular}{|c|c|c|c|c|c|c|c|c|c|}
\hline & Partido & Núcleo & $\begin{array}{l}\text { Cantidad de } \\
\text { parcelas }\end{array}$ & $\begin{array}{c}\text { Superficie } \\
\text { de la parcela } \\
\text { (en m2) }\end{array}$ & $\begin{array}{c}\text { Dimensión } \\
\text { del núcleo } \\
\text { (en ha) }\end{array}$ & $\begin{array}{c}\text { valor } \\
\text { economico } \\
\text { de la parcela } \\
\text { (en \$) } \times \text { mes }\end{array}$ & $\begin{array}{c}\text { Año de } \\
\text { realización } \\
\text { del ler loteo }\end{array}$ & Tipología & $\begin{array}{l}\text { distancia a } \\
\text { la Capital }\end{array}$ \\
\hline 37 & Merlo & Pradera de Merlo & 500 & 900 & 45 & $\$ 250$ & 1950 & $S / D$ & \\
\hline 38 & Merlo & San Antonio de Padua & 0 & 0 & 0 & $\$ 24$ & & P.P & 28 \\
\hline 39 & Merlo & B.P. San Martin & 1.000 & 400 & 40 & $\$ 8$ & & & \\
\hline 40 & Moreno & El Ensueño & 240 & 1.800 & 43,2 & $\$ 25$ & 1947 & L.S. & 45 \\
\hline 41 & Moreno & Rancho Grande & 300 & 1.000 & 30 & $\$ 25$ & 1947 & L.S. & 34 \\
\hline 42 & Moreno & Santa Teresa & 300 & 800 & 24 & $\$ 80$ & 1948 & L.S. & 35 \\
\hline 43 & Moreno & Parque Trujui & 26 & 2.000 & 5,2 & $\$ 100$ & 1949 & L.S. & 34 \\
\hline 44 & Moreno & Juan Pastorini & 23 & 800 & 1,84 & $\$ 90$ & 1950 & P.P & 35 \\
\hline 45 & Moreno & Las Catonas & & & 20 & $\$ 30$ & & L.S. & 23 \\
\hline 46 & Moreno & Los Nogales & 120 & 800 & 9,6 & $\$ 30$ & 1949 & P.P & 34 \\
\hline 47 & Morón & Alto Verde & 128 & 500 & 6,4 & $\$ 3$ & 1945 & L.S. & 31 \\
\hline 48 & Morón & Francisco Verde & 300 & 500 & 15 & $\$ 10$ & 1945 & L.S. & 30 \\
\hline 49 & Morón & Parque Leloir & 500 & 2.250 & 112,5 & $\$ 100$ & 1947 & L.S. & 30 \\
\hline 50 & Morón & Ituzaingo Residencial & 9 & 500 & 0,45 & $\$ 40$ & 1947 & P.P & 30 \\
\hline 51 & Morón & B.P. Castelar & 620 & 400 & 24,8 & $\$ 20$ & 1929 & C.N.P. & 25 \\
\hline 52 & Morón & Parque Quirno & 230 & 1.000 & 23 & $\$ 10$ & 1947 & L.S. & 30 \\
\hline 53 & Morón & B.P.San Francisco & 260 & 800 & 20,8 & $\$ 30$ & 1947 & L.S. & 29 \\
\hline 54 & Morón & B.P.Lomas de Castelar & 150 & 1.000 & 15 & & 1943 & L.S & 25 \\
\hline 55 & Morón & Parque Guiraldes & 133 & 1.200 & 15,96 & $\$ 40$ & 1946 & L.S. & 30 \\
\hline 56 & Morón & B.P. Maupas & 200 & 800 & 16 & $\$ 12$ & 1948 & L.S. & 31 \\
\hline 57 & Morón & Parque Morón & 1.000 & 400 & 40 & $\$ 6$ & 1932 & L.S. & 27 \\
\hline 58 & Morón & Nuevo B.P. G.Alvear & 120 & 800 & 9,6 & $\$ 20$ & & $P . P$ & 25 \\
\hline 59 & Morón & Morón Week-end & 196 & 500 & 9,8 & $\$ 10$ & 1945 & L.S. & 22 \\
\hline 60 & Morón & Lomas de Haedo & 197 & 800 & 15,76 & $\$ 5$ & 1945 & L.S. & 20 \\
\hline 61 & Morón & Villa Ariza & 0 & 0 & 50 & $\$ 0$ & 1939 & & 22 \\
\hline 62 & Morón & Los Angeles & 195 & 400 & 7,8 & $\$ 2$ & 1945 & L.S. & 24 \\
\hline 63 & Quilmes & B.P.Jacarandá & 1.400 & 300 & 42 & $\$ 20$ & 1949 & L.S. & 19 \\
\hline 64 & Quilmes & San Juan Pereyra & 30 & 3.000 & 9 & $150(45)$ & 1946 & L.S. & 20 \\
\hline 65 & Quilmes & Balneario Quilmes & 200 & 500 & 10 & $\$ 80$ & 1947 & L.S. & 18 \\
\hline 66 & San Fernando & La Floresta & 90 & 400 & 3,6 & $\$ 15$ & 1950 & $S / D$ & 26 \\
\hline 67 & San Isidro & B.P.Elortondo & 51 & 400 & 2,04 & $160(64)$ & 1931 & P.P & 21 \\
\hline 68 & San Isidro & B.P. Nelson & 51 & 400 & 2,04 & $s / d$ & 1934 & P.P & 21 \\
\hline 69 & San Isidro & B.P. Atalaya & 10 & 800 & 0,8 & $250(50)$ & 1949 & P.P & 22 \\
\hline 70 & San Isidro & B.P.Aguirre & 300 & 600 & 18 & $250(50)$ & 1920 & N.E & 22 \\
\hline 71 & San Isidro & B.P. Balcarce & 107 & 600 & 6,42 & $170(34)$ & 1935 & P.P & 21 \\
\hline 72 & San Isidro & B.P. Longchamps & 158 & 500 & 7,9 & $180(72)$ & 1945 & P.P & 22 \\
\hline
\end{tabular}

Fuente: Elaboración propia a partii de datos del Departamento de Investigación Histórica Cartográfica de la Dirección de Geodesia del Ministerio de Obras Públicas de la Provincia de Buenos Aires. 
Cuadro 1 - Relevamiento de loteos de tipo barrio parque entre 1910-1950

\begin{tabular}{|c|c|c|c|c|c|c|c|c|c|}
\hline & Partido & Núcleo & $\begin{array}{c}\text { Cantidad de } \\
\text { parcelas }\end{array}$ & $\begin{array}{c}\text { Superficie } \\
\text { de la parcela } \\
\text { (en } \mathrm{m} 2 \text { ) }\end{array}$ & $\begin{array}{l}\text { Dimensión } \\
\text { del núcleo } \\
\text { (en ha) }\end{array}$ & \begin{tabular}{|c|} 
valor \\
economico \\
de la parcela \\
(en \$) $\times$ mes
\end{tabular} & $\begin{array}{c}\text { Año de } \\
\text { realización } \\
\text { del ler loteo }\end{array}$ & Tipología & $\begin{array}{l}\text { distancia a } \\
\text { la Capital }\end{array}$ \\
\hline 73 & San Isidro & B.P. Santa Rosa & 63 & 1.000 & 6,3 & $\$ 100$ & 1945 & P.P & 24 \\
\hline 74 & San Isidro & B.P. Federico Alvear & 156 & 1.500 & 23,4 & $\$ 250$ & & L.S. & 27 \\
\hline 75 & San Isidro & B.P ViVot & $s / d$ & $s / d$ & 6 & $125(25)$ & 1935 & P.P & 21 \\
\hline 76 & San Isidro & B.P. Alvear & 0 & 350 & 5 & $\$ 300$ & 1940 & P.P. & 24 \\
\hline 77 & San Martín & Villa Bosch & 500 & 600 & 30 & $\$ 6$ & 1934 & N.E & 17 \\
\hline 78 & San Martín & $\begin{array}{l}\text { C.J. Lomas de } \\
\text { Palomar }\end{array}$ & & 700 & 35 & $\$ 0$ & 1946 & C.N.P. & 24 \\
\hline 79 & San Martín & Parque Villegas & 523 & 400 & 20,92 & $\$ 4$ & 1942 & P.P & 21 \\
\hline 80 & Tigre & Parque Sancalal & 200 & 1.300 & 26 & $\$ 40$ & 1948 & L.S. & 28 \\
\hline 81 & Tigre & B.P. Guadalupe & 400 & & & $\$ 40$ & 1948 & L.S. & 29 \\
\hline
\end{tabular}

Fuente: Elaboración propia a partir de datos del Departamento de Investigación Histórica Cartográfica de la Dirección de Geodesia del Ministerio de Obras Públicas de la Provincia de Buenos Aires.

libre y se podría "dibujar" el trazado al igual que si fuera un plano en una hoja blanca.

Sin embargo, la mayor parte de los pueblos que estructuraron el crecimiento del GBA ya existían para la década de 1910, aunque muchas veces sus formas eran aún precarias, con el establecimiento de una estación de ferrocarril o algunas quintas. El crecimiento que comenzó a experimentarse en ese período se gestó superponiendo pequeños trazados autónomos en las áreas vacantes que dejaban las pocas vías existentes, generalmente, en lo que hasta ese momento se consideraba la zona periférica de quintas.

Si analizamos el caso de Castelar, el trazado del Barrio Parque de 1929 se ubicó en una zona lateral del punto que hasta ese momento constituía el núcleo central del pueblo (Figura 4). Como resultado de esta incorporación, el Barrio Parque comenzó a conformar su propia "área central" y una periferia que, rápidamente, entró en contacto con la zona de la estación del tren, núcleo que históricamente constituía el área central del poblado. En síntesis, lo que este caso nos permite demostrar es la dificultad de pensar este tipo de expansión metropolitana en términos de un área urbana y unas quintas, a la manera de la ciudad colonial. Por el contrario, el tipo de expansión que aquí analizamos se superpuso a otra expansión que ya había tenido lugar - la de los primeros pueblos de campaña

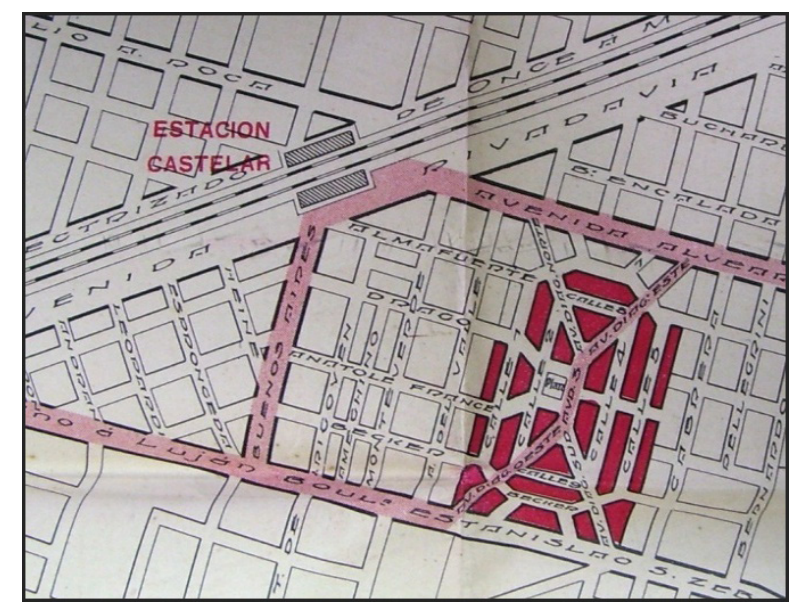

Figura 4 - Plano de ubicación del Barrio Parque Castelar en relación a la Estación Castelar del FCO

Fuente: Carpeta de Remates, Partido de Morón, en Departamento de Investigación Histórica Cartográfica de la Dirección de Geodesia del Ministerio de Obras Públicas de la Provincia de Buenos Aires.

y pueblos ferroviarios - imagen seguramente presente en el pensamiento de los actores que elaboraron la ley de 1913, consolidando un modelo de crecimiento que llevaba la marca de los topógrafos y de la lógica técnica del siglo XIX justo en el momento en que se tornaba obsoleta. Se reconoce, entonces, la inercia y pervivencia de medidas y acciones de una tradición reguladora anterior que, en los hechos, produjeron una tensión como consecuencia del desconocimiento de la realidad sobre la cual se llevaba a cabo la expansión. 
Sólo en los núcleos que se consolidaron junto a las nuevas estaciones sería posible pensar en la matriz de crecimiento ordenado que establecía la ley de formación de pueblos de 1913. Aunque, como ya hemos señalado, durante el siglo XX los ejemplos de este tipo fueron escasos y no lograron constituir áreas significativas dentro de la expansión ${ }^{20}$. Si bien existieron entonces algunos núcleos centrales dentro de la expansión - generalmente en torno a las estaciones del ferrocarril - y lo que podía entenderse como sus áreas periféricas, también es cierto que como señalamos en la introducción y como permiten observar los casos que mostramos- la mayor parte de los nuevos emprendimientos comprendieron áreas relativamente pequeñas, que se asentaron en los bordes de los pueblos originales o en zonas intersticiales entre un núcleo y otro.

De esto se desprende lo que denominamos un tema de "prioridades." Lo que para la ley de 1913 constituyó el segundo núcleo de preocupación - "la ampliación de ejidos" - y por lo tanto, se reconocía un mayor grado de indeterminación legal por el tipo de expansión fragmentaria que atravesó el GBA, terminó por afectar a la mayor parte de los loteos, ya que gran parte de estos no conformaron nuevos centros de población, sino que quedaron enmarcados como ampliación de ejido o dentro de lo que la legislación determinaba como zona de quintas o chacras. Concretamente, esto

${ }^{20}$ Uno de los pocos casos que puede citarse dentro de este grupo fue el Barrio Parque Aguirre (1913-1920) junto a la Estación Hipódromo en San Isidro (actualmente Estación Acassuso). Incluso, durante los años treinta y cuarenta el área terminó de consolidarse en relación a un número creciente de loteos menores que se incorporaron en las áreas vacantes entre el barrio mencionado y el núcleo original de San Isidro. Con el correr de los años, fueron cada vez más significativos los emprendimientos de áreas menores. Si bien exceden nuestro período de estudio vale la pena mencionar como ejemplo el área de la Estación de Don Torcuato, en donde se asistió a la incorporación de diferentes loteos de barrios parque (Barrio Parque Sancalal, 1948; Barrio Parque Guadalupe, 1948; Barrio Los Nogales, 1949) en áreas vacantes cercanas al trazado en retícula que rodea las estaciones. 0 , como se observa en el partido de La Matanza, la localización de sucesivos núcleos de barrios parque (Barrio Parque Peluffo, 1945; Barrio Parque San Eduardo, 1947; Los Pinos, 1947; Barrio Parque Peluffo (ampliación), 1947; La Ganga, 1947) que ocuparon un sector intersticial entre los ejes demarcados por las vías férreas, accesible gracias a la apertura operada en los años cuarenta por las vías de tránsito automotor. implicó, entre otras cosas, la posibilidad de eximirse de ceder tierras para reserva urbana ${ }^{21}$.

Los trámites realizados ante la Dirección de Geodesia del MOP para la aprobación del trazado del Barrio del Golf Ituzaingo (San Antonio de Padua, 1931) nos proveen información detallada para ilustrar esta situación (IAHMM, 1931). En el año 1931 el ingeniero Armando Frhener, autorizado por la Compañía de Tierras del Oeste, solicitó ante el Director de Geodesia y Catastro la aprobación del plano del "Barrio del Golf" (IAHMM, 1931).

Se solicita en esta actuación autorización para ampliar el pueblo de San Antonio de Padua, creando el llamado "Barrio del Golf" en terrenos de la mencionada Compañía, ubicados en el partido de Merlo. Se trata de regularizar hechos existentes, ya que varios propietarios han comprado lotes, edificado y plantado árboles de buena fe y a fin de no dañar sus intereses y allanar en lo posible las dificultades de la Compañía, por cuya razón pido se contemple lo relacionado con el trazado de las calles que no tienen el ancho reglamentario. Los lotes del nuevo proyecto tiene todos frente mínimo de 10mts con excepción de unos pocos que no se pudieron modificar por estar vendidos. Se agrega copia del proyecto en tela y dos copias [...] Confío que el Sr. Director quiera considerar la necesidad de regularizar la actual situación en el sentido de allanar en lo posible las dificultades y contribuir a la buena fe de la Compañía de Tierras con una resolución favorable que venga a sanear un estado de cosas que puede ser causa de confusiones y pleitos [...] Se considera también que no le corresponde a la Compañía de Tierras la cesión de Reservas para uso Público considerando la pequeña cantidad de terreno propiedad de la misma y el hecho de que el pueblo de San Antonio ya posee escuela, iglesia y comisaría en las inmediaciones de los terrenos en cuestión. Además cuando la Municipalidad aprobó los planos presentados por el Sr. Benavides no obligó a DíazValdéz (a la sazón propietario de las tierras) a ceder las reservas antes mencionadas. (IAHMM, 1931).

\footnotetext{
${ }^{21}$ Art. 13. en las zonas de ampliación, el Poder Ejecutivo podrá eximir al propietario de la obligación de dejar alguna o algunas de las reservas indicadas en el Artículo 14 de esta ley (Buenos Aires, 1927).
} 
La aprobación definitiva del barrio llegó en 1936. El plano presentado fue aceptado a pesar del incumplimiento en relación a las medidas de algunos lotes y calles, y se exigió escriturar a favor del fisco una parte de las reservas correspondientes (IAHMM, 1931).

Si bien la resolución final del caso mostró la voluntad de hacer respetar ciertas normas, también es posible esgrimir que algunas "licencias o excepciones", como la medida de los lotes o el porcentaje de reservas que se cedían al Municipio, eran admitidas como prácticas cotidianas. En este sentido, si tensionamos al máximo esta posibilidad de exención, podemos imaginar como resultado la materialización de áreas suburbanas continuas, conformadas a partir de la sumatoria de sucesivos loteos de pequeñas dimensiones, carentes, completamente, de reservas para el uso público.

\section{A modo de conclusión}

Como hemos señalado al inicio del artículo, la forma de expansión predominante en el Área Metropolitana se llevó a cabo a través de la subdivisión de lotes en manos de agentes privados, a los cuales años más tarde le llegaban los servicios y se construían las viviendas. Si bien es cierto que esta modalidad otorgó especial protagonismo a los actores privados, la participación del Estado provincial no debe ser soslayada o minimizada, dado que proveyó de un marco regulatorio dentro del cual debían llevarse a cabo las acciones, prácticas y operaciones privadas que mencionamos.

A pesar de lo que los propios actores y las lecturas más tradicionales señalaron la falta de legislación y de controles estatales para regular la expansión frente a los intereses particulares, hemos visto que a partir del siglo XIX y de manera creciente, comenzaron a organizarse una serie de normativas y reglamentos tendientes a controlar y a ordenar el desarrollo territorial. Estos expresaron, por un lado, cambios paulatinos en las funciones del Estado (por ejemplo, una mayor capacidad de regulación) y, por el otro, el interés de gobiernos de distintas orientaciones políticas por dar solución a los problemas que traía aparejada la fundación de pueblos sin control oficial. Sin embargo, lo que no se verificó de igual forma fue la adecuación de las normas al diagnóstico de la expansión. De esta manera, en lo que se refiere a la actuación del Estado en la configuración del territorio, pueden señalarse una falta de adecuación entre las acciones propuestas y las posibilidades concretas de llevarlas a cabo, y una carencia de sensibilidad para leer las coordenadas de la expansión y actuar en consecuencia.

En relación al primer tema, la incapacidad para llevar a cabo la gestión y los controles que aseguraran el correcto cumplimiento de las reglamentaciones se reflejó en la dificultad de coordinar y establecer jerarquías concretas entre el accionar de los diferentes organismos de la órbita provincial y los actores del ámbito local. Este problema revela, a su vez, la dificultad de cumplir con el ciclo de las políticas públicas, que señalamos pertinentemente; pero también uno más amplio que ha atravesado a la historia de la provincia de Buenos Aires: la compleja relación entre la provincia y los actores locales.

En relación al segundo núcleo problemático, además de juzgar la implementación o el cumplimiento de la legislación, lo que se revela al contrastar los contenidos que ella propone con las formas en que se llevó a cabo la expansión, es que la legislación tendió a ofrecer una imagen simplificadora, que daba cuenta, por un lado, de una deuda con la tradición reguladora de los topógrafos del siglo XIX. Por otro, ponía en cuestión las dificultades y limitaciones que tuvieron los actores impulsores y gestores de la legislación para observar y pensar la complejidad y las múltiples dimensiones de la expansión moderna. Esto provocó, como hemos observado, un contraste entre las normas y las prácticas.

Por último, se verifica que una vez establecidas, las normativas y los organismos estatales encargados de llevarlas a cabo tendieron a perdurar. En este sentido conviene no confundir las ideas con las prácticas. Es decir, que algunas de las propuestas que surgieron como propias del "clima de ideas" vigente al momento de la concepción de la ley, terminan por ponerse en práctica en contextos diferentes. Por ende, su influencia fue más allá del "clima de ideas", de las orientaciones políticas $\mathrm{y}$ de las condiciones particulares que propiciaron su surgimiento a comienzos del siglo XX. Consideramos que más allá de su grado de observancia, una vez que ciertas ideas son trasladadas al papel son tomadas como estándar y reproducidas a través de cuerpos técnicos que operan en representación del Estado, incidiendo de hecho en la configuración del territorio. 


\section{Referencias}

Aguilar Villanueva, L. (1993). Estudio introductorio. In L. Aguilar Villanueva (Ed.), La implementación de las políticas públicas. México: Miguel Ángel Porrúa.

Aliata, F. (2004). Departamento topográfico. In J. Liernur, \& F. Aliata (Eds.), Diccionario de Arquitectura en la Argentina. Buenos Aires: Clarín.

Aliata, F. (2006). La ciudad regular: arquitectura, programas e instituciones en el Buenos Aires posrevolucionario, 18211835. Buenos Aires: Universidad Nacional de Quilmes y Prometeo.

Ballent, A. (2008). Ingeniería y Estado: la red nacional de caminos y las obras públicas en la Argentina, 1930-1943. História, Ciências, Saúde-Manguinhos, 15(3), 827-847. http://dx.doi.org/10.1590/S0104-59702008000300013.

Ballent, A., \& Gorelik, A. (2001). País Urbano y país rural: la modernización del país y su crisis. In A. Cattaruzza (Ed.), Crisis Económica, avance el Estado e Incertidumbre Política. (1930-1943) (Colección Nueva Historia Argentina). Buenos Aires: Editorial Sudamericana.

Barba, F. \& DemaríaMassey, M. E. (1987). La provincia de Buenos Aires, 1910-1987. La Plata: Dirección de Servicios Generales del Ministerio de Economía de la Provincia de Buenos Aires.

Bevilacqua de Cristino, C. (1993). Procesos de producción y consumo de tierra urbana en la periferia del área metropolitana de Buenos Aires: el caso del municipio de Almirante Brown 1948-1972 (Serie Estudio. Investigaciones, No. 14). La Plata: Universidad Nacional de La Plata.

Bohoslavsky, E., \& Soprano, G. (2010). Un Estado con rostro humano: funcionarios e instituciones estatales en Argentina (desde 1880 hasta la actualidad). Buenos Aires: Prometeo-UNGS.

Bourdieu, P., \& Wacquant, L. (2005). Una invitación a la sociología reflexiva. Buenos Aires: Siglo XXI.

Buenos Aires. Cámara de Senadores. (1913a). Diario de Sesiones. La Plata: Taller de Impresiones Oficiales

Buenos Aires. (1913b). Ley $n^{\circ}$ 3487: fundación de pueblos. La Plata: Taller de Impresiones Oficiales. Registro Oficial.

Buenos Aires. Cámara de Senadores. (1922). Diario de Sesiones. La Plata: Taller de Impresiones Oficiales.
Buenos Aires. (1927, 26 de octubre). Decreto Reglamentario, 26/10/1927, a la Ley de Fundación de Pueblos y Ampliación de Ejidos $n^{\circ} 3487,13 / 11 / 1913$. Buenos Aires.

Camou, A. (1997). Los consejeros del príncipe: saber técnico y política en los procesos de reforma económica en América Latina. Nueva Sociedad, 152, 54-67.

Caride, H. (1977). La construcción de una idea: El conurbano bonaerense, 1925-1947 (Colección Crítica, No. 76). Buenos Aires: IAA.

Clichevsky, N. (1975). El mercado de tierras en el área de la expansión de Buenos Aires y su incidencia sobre los sectores populares, período 1943-1973. Buenos Aires: Centro de Estudios Urbanos y Regionales, Instituto Torcuato Di Tella.

Clichevsky, N. (2002). Tierra Vacante en Ciudades Latinoamericanas. Toronto: Nora Clichevsky Editora.

Clichevsky, N., Schapira, P., \& Schneier, G. (1990). Loteos populares, sector inmobiliario y gestión local en Buenos Aires. El caso del municipio de Moreno. Buenos Aires: Cuadernos del CEUR.

Favelukes, G. (2011). Figuras y paradigmas. Las formas de Buenos Aires (1740-1870). Anales del Instituto de Arte Americano e Investigaciones Estéticas "Mario J. Buschiazzo", 41,11-26. Recuperado el 03 de febrero de 2015, de http:// www.iaa.fadu.uba.ar/ojs/index.php/anales/article/view/45

Gómez Pintus, A. (2013). Las lógicas privadas de la expansión: loteos de barrios parque en el área metropolitana de Buenos Aires 1910-1950. Revista Registros, 10, 75-94. Recuperado el 03 de febrero de 2015, de http://faud.mdp. edu.ar/revistas/index.php/registros/article/view/176

Gómez Pintus, A. (2014). Hacia una tipología de las urbanizaciones de fin de semana: Barrios Parque y urbanizaciones de week-end en la formación del área metropolitana 1910-1950. Revista Estudios del Hábitat, 12, 47-61. Recuperado el 03 de febrero de 2015, de http:// revistas.unlp.edu.ar/Habitat/article/view/1132

Gorelik, A. (1998). La Grilla y el parque. Espacio público y cultura en Buenos Aires. Buenos Aires: Universidad Nacional de Quilmes/Prometeo.

Gorelik, A. (2009). Roles de la periferia. Buenos Aires: de ciudad expansiva a ciudad archipiélago. In International Conference Peripheries: Decentering Urban Theory. Berkeley: University of California.

Hall, P. (1996). Ciudades del Mañana: historia del Urbanismo en el Siglo XX. Barcelona: Ediciones del Serbal. 
Hora, R. (2001). Autonomistas, radicales y mitristas: el orden oligárquico en la provincia de Buenos Aires. Boletín del Instituto de Historia Argentina y Americana Dr. Emilio Ravignan, 3(23), 39-78.

Instituto y Archivo Histórico Municipal de Morón - IAHMM. (1931). Mensura, duplicado no 54. Buenos Aires.

Lanciotti, N. (2009). De rentistas a empresarios: inversión inmobiliaria y urbanización en la pampa argentina. Rosario, 1880-1910. Rosario: Edición de la Universidad Nacional del Litoral.

Mann, M. (1991). El poder autónomo del Estado, sus orígenes, mecanismos y resultados. Zona Abierta, 57-58, 15-50.

Mazza, C. (1997). La ciudad de papel: análisis histórico de normativas y planes urbanos para la ciudad de Mar del Plata, 1885-1975. Mar del Plata: Facultad de Arquitectura, Urbanismo y Diseño, UNMdP.

Míguez, E. (2013). La provincia de Buenos Aires entre 1880 y 1943. In J.M. Palacio (Ed.), Historia de la Provincia de Buenos Aires: de la federalización al advenimiento del peronismo (1880-1943). Tomo 4. Buenos Aires: UNIPE-Edhasa.

Oszlak, O. (2006). Burocracia estatal: política y políticas públicas. POSTData Revista de Reflexión y Análisis Político, (11), 1-30.

Oszlak, O., \& O’Donnell, O. (1984). Políticas públicas y regímenes políticos: reflexiones a partir de algunas experiencias latinoamericanas. Buenos Aires: CEDES.

Pastor, J. M., \& Bonilla, J. (1958). Estudio sobre el uso de la tierra. Buenos Aires: Instituto de Planeamiento Regional y Urbano.

Persello, A. V. (2006). Partidos políticos y corporaciones: las Juntas Reguladoras de producción, 1930-1943. Boletín del Instituto de Historia Emilio Ravignani, (29), 85-118.

Rein, M., \& Rabinovitz, F. (1993). La implementación: una perspectiva teórica entre la intención y la acción. In L. Aguilar Villanueva (Ed.), La implementación de las políticas públicas. México: Miguel Ángel Porrúa.

Romero, J. L. (2009). La ciudad occidental: culturas urbanas en Europa y América. Buenos Aires: Siglo XXI.

Rosanvallon, P. (1989). L'etat en France de 1798 a nousjours. París: Éditions du Seuil.
Sargent, C. H. (1974). The Spatial Evolution of Greater Buenos Aires, 1870-1930. Arizona: Center for Latin America Studies, Arizona State University.

Schteingart, M., \& Torres, H. (1972). Procesos sociales y estructuración metropolitana en América Latina: estudios de caso. Desarrollo Económico, 48(12), 725-769. Recuperado el 03 de febrero de 2015, de http://www.jstor. org/stable/3466302

Sikkink, K., \& Wolfson, L. (1993). Las capacidades y la autonomía del Estado en Brasil y la Argentina: un enfoque neoinstitucionalista. Desarrollo Economico, 32(128), 543. http://dx.doi.org/10.2307/3467177.

Simmel, G. (1986). Las grandes urbes y la vida del espíritu. In G. Simmel, El individuo y la libertad: ensayos de crítica de la cultura. Barcelona: Península.

Skinner, Q. (2003). El nacimiento del Estado. Buenos Aires: Gorla.

Skocpol, T., Evans, P. B., \& Rueschemeyer, D. (1985). Bringing the state back in: strategies of analysis in current research. In P. Evans, D. Rueschemeyer \& T.H. Skocpol (Eds.), Bringing the state back in. Cambridge: Cambridge University Press.. http://dx.doi.org/10.1017/CB09780511628283.002.

Torres, H. (1975). Evolución de los procesos de estructuración espacial urbana: el caso de la ciudad de Buenos Aires. Desarrollo Economico, 15(58), 281-306. http://dx.doi. org/10.2307/3466262.

Torres, H. (1993). El mapa social de Buenos Aires. 19401990 (Serie Difusión, No. 3). Buenos Aires: Facultad de Arquitectura y Urbanismo.

Van Meter, D., \& Van Horn, C. (1993). El proceso de implementación de las políticas: un marco conceptual. In L. Aguilar Villanueva (Ed.), La implementación de las políticas públicas. México: Miguel Ángel Porrúa.

Vapñarsky, C. (2000). La aglomeración Gran Buenos Aires: expansión espacial y crecimiento demográfico entre 1869 y 1991. Buenos Aires: Eudeba.

Yujnovsky, O. (1971). La estructura interna de la ciudad: el caso Latinoamericano. Buenos Aires: Facultad de Arquitectura y Urbanismo.

Recibido: Feb. 03, 2015

Aprobado: Agosto 04, 2015 